\title{
Comparison of the composition and fungicidal activity of essential oils from fennel fruits cultivated in Poland and Egypt
}

\author{
Alicja Wodnicka ${ }^{1 *}$, Elżbieta Huzar ${ }^{1}$, Małgorzata Dzięcioł ${ }^{1}$, Maria Krawczyk ${ }^{2}$ \\ ${ }^{1}$ West Pomeranian University of Technology, Szczecin, Faculty of Chemical Technology and Engineering, Institute of \\ Organic Chemical Technology, Al. Piastów 42, 71-065 Szczecin, Poland \\ ${ }^{2}$ Institute of Industrial Organic Chemistry, Annopol 6, 03-236 Warsaw, Poland \\ "Corresponding author: e-mail: alicja.wodnicka@zut.edu.pl
}

\begin{abstract}
The yield, composition and fungicidal activity of essential oils obtained from fennel fruits cultivated in Poland (FEOPOL) and Egypt (FEO-EG) were compared. The influence of the duration of hydrodistillation using a Clevenger apparatus on the essential oil yield was studied. The composition of the fennel essential oils was determined by GC-MS method. Studies have shown that FEO-POL and FEO-EG are two distinct chemotypes, which differ in yield and composition. The fennel fruits cultivated in Poland contained $4.14 \%$ of essential oil with trans-anethole as a main component. The plant material from Egypt was characterised by low content of essential oil $(1.32 \%)$ with a predominant share of estragole. The fungicidal activity was tested in vitro against ten species of pathogenic fungi. The best result for FEO-POL was achieved against Sclerotinia sclerotiorum, Rhizoctonia solani and Botrytis cinerea. Antifungal activity of FEO-EG against tested fungi was weak or none.
\end{abstract}

Keywords: fennel essential oil, Foeniculum vulgare Mill., fungicidal activity, trans-anethole, estragole.

\section{INTRODUCTION}

Fennel (Foeniculum vulgare Mill.) is an aromatic plant that grows all over the world and is widely used as a spice. In cuisine, various anatomical parts of fennel are used. Fragrant substances with a pleasant smell and taste are located mainly in the fruits, but also in the stems and leaves. They are used to flavour beverages, bread, pickles, pastries, cheese and other food products ${ }^{1}$.

Due to its pharmacological properties, herbs and the fruits of fennel are also used in folk and natural medicine. Particularly valuable are fennel fruits, which are characterised by a significant content of essential oil. Traditionally, fennel fruits are used as anti-inflammatory, analgesic, carminative, secretolytic, diuretic and antispasmodic agents ${ }^{2,3}$. Fennel essential oil and medical drugs based on fennel are also known for their hepatoprotective properties $^{4}$ and anticancer effects, ${ }^{5,6}$. Antimicrobial and antifungal activities of the essential oil from fennel and its components against some popular and opportunistic pathogens were also found. Fennel essential oil shows strong bactericidal activity against Escherichia coli, Salmonella typhimurium, Staphylococcus aureus, Staphylococcus albus, Helicobacter pylori, Pseudomonas syringae, Bacillus subtilis, Shigella dysenteriae and other bacteria ${ }^{7-11}$. It is also very effective against different fungi, e.g. Cladosporium cladosporioides, Phomopsis helianthi, Trichophyton mentagrophytes, Trichophyton rubrum, Aspergillus niger, Aspergillus flavus, Aspergillus fumigatus, Fusarium graminearum, Fusarium solani, Fusarium moniliforme, Alternaria, Aureobasidium, Penicillium, Phytophthora infestans, Rhizopus solani, Sclerotinia sclerotiorum ${ }^{2,11-13}$.

An important factor determining the biological activity of fennel essential oil is the great variability of its composition. Studies have shown that this depends significantly on geographical origins and is affected by genetic and environmental factors ${ }^{1,14}$. The aim of this study was to compare the yield, composition and fungicidal activity of essential oils obtained from fruits of fennel cultivated in Poland and Egypt. Their antifungal properties against 10 different strains of popular pathogens were determined.
The tested microorganisms are known as mycotoxigenic, causing plant diseases or biodeterioration of technical materials.

\section{EXPERIMENTAL}

\section{Materials and chemicals}

Fennel fruits (Foeniculum vulgare Mill.) from two different countries were used as a source of essential oil. The plant material cultivated in Poland was obtained from Plant Herb KAWON-HURT Nowak sp.j. (Gostyń, Poland). The plant material from Egypt was purchased from an online shop: Real Foods (Edinburgh, Scotland, United Kingdom). According to the producers' information, the fennel was grown and harvested in 2015. Essential oils from fruits of fennel cultivated in Poland (FEO-POL) and in Egypt (FEO-EG) were obtained in January 2016. Before essential oil isolation, fennel fruits were stored at room temperature and protected from light.

For the identification of the essential oil ingredients, the following standards were used: trans-anethole (99\%), camphene $(\geq 90 \%), p$-cymene $(99 \%), \alpha$-phellandrene $(\geq 85 \%)$, R-(+)-limonene (97\%), $\alpha$-pinene (98\%), sabinene (natural $75 \%$ ) and $\gamma$-terpinene $(97 \%)$ from Sigma-Aldrich (Steinheim, Germany), and camphor (natural pure) from International Enzymes Limited (Windsor, Berkshire, England). In order to determine the linear retention indices of the essential oil components, the saturated $n$-alkanes standard $\mathrm{C}_{7}-\mathrm{C}_{30}$ purchased from Supelco (Bellefonte, Pennsylvania, USA) was applied.

Additional chemicals included anhydrous sodium sulfate (pure p.a.) from POCH (Gliwice, Poland), which was used as a drying agent to remove the water from essential oil samples, and acetone (pure p.a.) from Chempur (Piekary Śląskie, Poland) as a solvent of essential oils for chromatographic analysis.

Cultures of fungi were obtained from: Bank of Plant Pathogens, Institute of Plant Protection, National Research Institute, Poznan: Alternaria alternata [1045], Bo- 
trytis cinerea [1636], Fusarium culmorum [600], Fusarium avenaceum [670], Rhizoctonia solani [642]; University of Life Sciences, Department of Plant Pathology, Warsaw: Fusarium graminarum, Phythophtora infestans, Sclerotinia sclerotiorum, Penicillium ochrochloron; Institute of Industrial Organic Chemistry, Department of Ecotoxicology, Pszczyna: Ascosphaera apis.

\section{Isolation of the essential oil}

The samples of fennel fruits were subjected to hydrodistillation using an all-glass Clevenger apparatus (WPL Gliwice, Poland) recommended by Polish Pharmacopoeia since its 7 th edition ${ }^{15}$. In order to extract the essential oil, $20 \mathrm{~g}$ of the ground fruits, $500 \mathrm{ml}$ of distilled water and some boiling stones were placed in a $1000 \mathrm{ml}$ round-bottom flask. Then, the flask was connected to the Clevenger apparatus. The fruits were ground immediately before the experiments to minimise essential oil losses. The hydrodistillation was performed at a rate of $3 \mathrm{ml} / \mathrm{min}$ for different periods of time ranging from 30 minutes to 3 hours. Essential oil yield was calculated on the basis of essential oil volume and plant material weight, and expressed in $\%(\mathrm{v} / \mathrm{w})$. The obtained essential oils were dried over anhydrous sodium sulfate and stored in sealed vials at $4^{\circ} \mathrm{C}$ until GC-MS analysis was performed. Prior to the analysis, the samples of essential oils $(20 \mu \mathrm{l})$ were dissolved in acetone $(1.0 \mathrm{ml})$ to obtain a concentration of about $19 \mathrm{mg} / \mathrm{ml}$. For each examined essential oil, three analytical samples were prepared.

\section{GC-MS analysis}

The GC-MS analysis of the essential oils was carried out using an Agilent 6890 gas chromatograph (Agilent Technologies, Palo Alto, California, USA) equipped with an Agilent 5973 Network Mass Selective Detector (MSD). The separation was performed using a HP-5MSI capillary column with bonded (5\% phenyl)-methylpolysiloxane stationary phase $(30 \mathrm{~m} \times 0.25 \mathrm{~mm}$ I.D., $0.25 \mu \mathrm{m}$ film thickness). The $\mathrm{GC}$ oven temperature was programmed from $50^{\circ} \mathrm{C}$ to $290^{\circ} \mathrm{C}$ at a rate of $4^{\circ} \mathrm{C} / \mathrm{min}$. Helium was used as a carrier gas at a constant flow rate of $1.2 \mathrm{ml} /$ min. A volume of $2 \mu \mathrm{l}$ of solution was injected in the split mode at a ratio of $10: 1$ at a temperature of $250^{\circ} \mathrm{C}$. The mass selective detector conditions were as follows: electron impact positive ionisation: $70 \mathrm{eV}$, full scan mode: mass range from 20 to $500 \mathrm{~m} / \mathrm{z}$, MSD transfer line temperature: $310^{\circ} \mathrm{C}$, MS quad: $150^{\circ} \mathrm{C}$, MS source: $230^{\circ} \mathrm{C}$. The mass selective detector was turned off during the first 3 minutes of analysis.

The linear retention indices (LRI) were calculated for all volatile constituents of essential oils using retention data of a homologous series of $n$-alkanes $\left(\mathrm{C}_{7}-\mathrm{C}_{30}\right)$. The obtained results were compared with data published in the literature ${ }^{16,17}$. The components of the essential oils were also identified by comparison of their mass spectra collected in the NIST 02 mass spectral library. Additionally, the identification was confirmed by the analysis of standards available in the laboratory.

The quantitative analysis was performed by the internal normalisation method without the application of correction factors. The relative percentage of the essential oil constituents was evaluated by a total ion chromatogram (TIC) using the MestReNova 10.0.2 software. The relative contents of particular compounds in essential oils were obtained as the percentages of a peak area in a total ion chromatogram.

\section{Antifungal tests}

The fungicidal activity of fennel essential oils was tested in the Institute of Industrial Organic Chemistry in Warsaw. Ten different species of fungi were used in the experiments, including eight plant pathogenic fungi: $A$. alternata, B. cinerea, $F$. avenaceum, $F$. culmorum, $F$. graminarum, $P$. infestans, $R$. solani, $S$. sclerotiorum, an important pathogen that affects honeybee brood $A$. apis and a mould causing the biodeterioration of technical materials $P$. ochrochloron. All strains of the fungi originated from the collection of the Institute. Antifungal activity of the essential oils was assayed in vitro using the agar growth medium poison technique. For this purpose, oil samples were dissolved in acetone and the solutions were mixed with molten Potato Dextrose Agar (PDA) growth medium after autoclaving in order to obtain concentrations of $1.0 \mathrm{mg} / \mathrm{ml}$. The homogeneous mixtures were poured in sterilised Petri dishes. The mycelial circle disk of fungi, taken from the edge of a 7-day-old culture, was inoculated at the centre of each plate after PDA solidification. After incubation at $25^{\circ} \mathrm{C}$ that lasted a few days, depending on the growth of mycelium in the control (PDA with acetone), the inhibitory effects of the oils on linear growth were determined by measuring the diameter of the fungal colony. The fungistatic activity of the tested compounds was expressed as a percentage inhibition of mycelium compared to the control. Each measurement consisted of three replications and the average percentage of mycelia inhibition was calculated.

\section{RESULTS AND DISCUSSION}

\section{Essential oils content and composition}

In the first stage of our research, the kinetics of the hydrodistillation was studied using the plant material from Poland. The yield of essential oil isolation was determined after different periods of time: 30, 60, 90 and 120 minutes (Fig. 1). Each experiment was repeated three times, the results were averaged, and the means were compared by using one-way analysis of variance

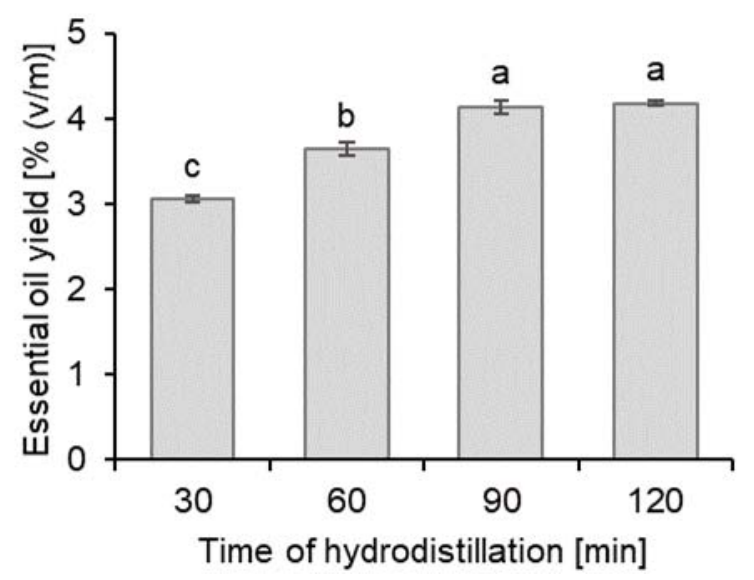

Figure 1. Influence of hydrodistillation duration on fennel essential oil yield (FEO-POL). Values marked with the same letter were not significantly different (Duncan's test, $\mathrm{p}>0.05$ ) 
(ANOVA) followed by Duncan's multiple range tests at the significance level of 0.05 using the software STATISTICA, version 12 (StatSoft, Inc., 2014). Leading the process of essential oil isolation for 30 minutes, the yield of $3.05 \pm 0.04 \%(\mathrm{v} / \mathrm{w})$ was reached. Prolonged distillation time resulted in significant increase of the yield to values of $3.64 \pm 0.08 \%(\mathrm{v} / \mathrm{w})$ for 60 minutes. Increasing hydrodistillation time to 90 and 120 minutes provided even higher yields of $4.14 \pm 0.08 \%(\mathrm{v} / \mathrm{w})$ and $4.18 \pm 0.03 \%(\mathrm{v} / \mathrm{w})$, respectively. However, the difference between these two yields was not significant $(\mathrm{p}>0.05)$.

Taking into account the kinetics of the fennel essential oil isolation, 90-minute experiments were performed to study the yield and composition of fennel essential oil from plant materials cultivated in Poland and Egypt. The results are presented in Table 1 . Twenty compounds, which accounted for more than $99 \%$ of fennel essential oils, were identified using the GC-MS method. The determined retention indices of the particular compounds were consistent with the literature $\mathbf{1 6}^{\mathbf{1 6}, \mathbf{1 7}}$. Identification was also confirmed by comparing the mass spectra with data from the NIST 02 library. A spectral match quality for different. According to the literature, high variability of fennel essential oil composition is observed. Piccaglia and Marotti $^{18}$ reported the predominant constituents of essential oils obtained from thirteen types of fennel. Their results confirm estragole, trans-anethole, fenchone and limonene as the main components of fennel essential oil; however, the content of these substances varied widely: estragole $(0.15-52.17 \%)$, trans-anethole $(0.14-42.26 \%)$, fenchone (1.70-11.22\%) and limonene (1.74-22.68\%). Additionally, the authors observed substantial content of $\alpha$-phellanderene $(0.31-82.07 \%)$ and $\alpha$-pinene $(0.75-26.54 \%)$. In the essential oils analyzed in the present study, the relative contents of these substances were significantly lower. Both FEO-POL and FEO-EG are characterised by a trace content of $\alpha$-phellanderene $(\leq 0.05 \%)$ and a low concentration of $\alpha$-pinene -2.88 and $0.72 \%$ respectively. Comparing our results with the literature, the plant material cultivated in Poland seems to be similar to the fennel grown in Turkey and $\operatorname{Iran}^{\mathbf{1 9}, \mathbf{2 0}}$. The determined composition of the essential oil obtained from the plant material cultivated in Egypt was consistent with the report of Afify et al. ${ }^{21}$.

Table 1. Yield and composition of essential oils from fruits of fennel cultivated in Poland (FEO-POL) and Egypt (FEO-EG)

\begin{tabular}{|c|c|c|c|c|c|}
\hline \multirow{2}{*}{ Compound } & \multicolumn{3}{|c|}{ Linear retention index } & \multicolumn{2}{|c|}{ Relative content \pm SD [\%] } \\
\hline & $\mathrm{LRI}^{\mathrm{a}}$ & $\mathrm{LRI}^{\mathrm{b}}$ & $\mathrm{LRI}^{\mathrm{c}}$ & FEO-POL & FEO-EG \\
\hline$\alpha$-Pinene & 930 & 932 & $936 \pm 8$ & $2.88 \pm 0.39$ & $0.72 \pm 0.08$ \\
\hline Camphene & 944 & 946 & $950 \pm 7$ & $0.18 \pm 0.02$ & $\operatorname{tr}$ \\
\hline Sabinene & 970 & 969 & $973 \pm 7$ & $0.25 \pm 0.03$ & $0.24 \pm 0.02$ \\
\hline$\beta$-Myrcene & 990 & 988 & $989 \pm 6$ & $0.39 \pm 0.02$ & $0.13 \pm 0.01$ \\
\hline$\alpha$-Phellandrene & 1004 & 1002 & $1004 \pm 7$ & $\operatorname{tr}$ & $\operatorname{tr}$ \\
\hline$p$-Cymene & 1023 & 1020 & $1024 \pm 7$ & $0.32 \pm 0.01$ & $\operatorname{tr}$ \\
\hline Limonene & 1026 & 1024 & $1030 \pm 7$ & $2.27 \pm 0.18$ & $8.63 \pm 0.26$ \\
\hline 1,8-Cineole & 1030 & 1026 & $1032 \pm 7$ & $\operatorname{tr}$ & $\operatorname{tr}$ \\
\hline cis- $\beta$-Ocimene & 1036 & 1032 & $1038 \pm 7$ & nd & $0.30 \pm 0.03$ \\
\hline$\gamma$-Terpinene & 1057 & 1054 & $1060 \pm 8$ & $0.18 \pm 0.02$ & $0.18 \pm 0.02$ \\
\hline Fenchone & 1093 & 1083 & $1088 \pm 6$ & $18.14 \pm 0.66$ & $1.96 \pm 0.05$ \\
\hline trans-Pinene hydrate & 1124 & 1119 & $1121 \pm 4$ & $\operatorname{tr}$ & nd \\
\hline cis-Limonene oxide & 1136 & 1132 & $1134 \pm 6$ & nd & $\operatorname{tr}$ \\
\hline trans-Limonene oxide & 1142 & 1137 & $1138 \pm 7$ & nd & $\operatorname{tr}$ \\
\hline Camphor & 1146 & 1141 & $1143 \pm 8$ & $0.30 \pm 0.01$ & $\operatorname{tr}$ \\
\hline Terpinen-4-ol & 1184 & 1177 & $1177 \pm 9$ & $\operatorname{tr}$ & nd \\
\hline Estragole & 1202 & 1195 & $1196 \pm 5$ & $2.64 \pm 0.01$ & $87.49 \pm 0.40$ \\
\hline exo-Fenchyl acetate & 1235 & 1229 & no data & nd & $\operatorname{tr}$ \\
\hline$p$-Anisaldehyde & 1258 & 1247 & $1252 \pm 9$ & $1.97 \pm 0.35$ & nd \\
\hline trans-Anethole & 1288 & 1282 & $1285 \pm 8$ & $69.95 \pm 0.59$ & nd \\
\hline \multicolumn{4}{|c|}{ Essential oil yield [\% (v/w)] } & $4.14 \pm 0.08$ & $1.32 \pm 0.02$ \\
\hline
\end{tabular}

$\mathrm{LRI}^{\mathrm{a}}$ - linear retention indices determined in relation to $\mathrm{C}_{7}-\mathrm{C}_{30}$ n-alkanes on the HP-5MSI capillary column; LRI ${ }^{\mathrm{b}}-$ retention indices from the literature ${ }^{16}$; LRIc - retention indices from the literature ${ }^{17}$; Relative content - percentage of the peak area in the total ion chromatogram; SD - standard deviation calculated from three separate tests; $t r$ - relative content $\leq 0.05 \%$; nd - not detected

the main components of the essential oils was above $90 \%$, and above $80 \%$ for minor constituents. The spectra and retention parameters were also confirmed by the analysis of nine standards.

As shown in Table 1, the content of essential oil from fennel cultivated in Poland was more than three times higher in comparison to plant material from Egypt, and their compositions were also different. The main component of FEO-POL was trans-anethole (relative content $69.95 \%$ ), while its isomer estragole was predominant component $(87.49 \%)$ in FEO-EG. FEO-POL contained also a substantial amount of fenchone (18.14\%), but FEO-EG contained $8.63 \%$ of limonene. The relative contents of other constituents in essential oils were below $3 \%$ and their distributions were also
Table 2. Effect of essential oils from fennel fruits cultivated in Poland (FEO-POL) and Egypt (FEO-EG) on the inhibition of fungi mycelia growth

\begin{tabular}{|l|c|c|}
\hline \multirow{2}{*}{ Fungi strain } & \multicolumn{2}{|c|}{ Mycelia growth inhibition* [\%] } \\
\cline { 2 - 3 } & FEO-POL & FEO-EG \\
\hline A. alternata & 16.6 & 0.0 \\
\hline B. cinerea & 60.0 & 16.6 \\
\hline F. avenaceum & 13.3 & 0.0 \\
\hline F. culmorum & 6.2 & 14.0 \\
\hline F. graminarum & 48.8 & 28.8 \\
\hline P. infestans & 28.5 & 14.2 \\
\hline R. solani & 80.0 & 20.0 \\
\hline S. sclerotiorum & 100.0 & 0.0 \\
\hline A. apis & 33.3 & 11.1 \\
\hline P. ochrochloron & 9.2 & 8.3 \\
\hline
\end{tabular}

*evaluation of activity: 0-20\% - no effect; $20.1-50 \%$ - weak activity; $50.1-90 \%$ - moderate activity; $90.1-100 \%$ - good activity 
The composition of an essential oil determines its physical and biological properties. trans-Anethole is an important component of the characteristically sweet aroma of fennel. It exhibits anti-inflammatory and anti-carcinogenic properties ${ }^{22}$. In turn, estragole was reported as a potential human carcinogen ${ }^{23}$; therefore, its presence in plant materials lowers essential oil quality and may increase health risks. Other studies suggest that, in natural products, the presence of other constituents forming a complex phytochemical mixture could play a protective role against the risk connected with estragole ${ }^{24}$. Nevertheless, taking into account its chemical composition, fennel essential oil originating from Poland seems to be more favourable. In this product, the content of estragole was low (below 3\%). The significantly high amount of fenchone with its specific bitter taste could be a basis to classify this fennel alongside the "bitter types"21. Both trans-anethole and estragole - the main components of the obtained essential oils have a common biosynthesis originating from the same precursors - L-phenylalanine and cinnamic acid ${ }^{\mathbf{1 8}}$ - and exhibit antimicrobial properties $^{25}$. Thus, the aim of this work was to determine the relationship between the composition of the particular oils and their activity against selected fungal strains.

\section{Fungicidal activity}

The results of antifungal tests are shown in Table 2. The essential oils showed varied activity against the tested strains of pathogenic fungi and, as can be seen, in all cases the product obtained from fennel cultivated in Poland was more active. Some effect of FEO-POL was observed for all tested strains, while in the case of FEO-EG only for seven of them. Activity higher than the limit stated of $20 \%$ was determined for FEO-POL against six pathogens and for FEO-EG only against one fungus strain $-F$. graminarum, but its activity was weak $(28.8 \%)$. FEO-POL showed weak activity against $F$. graminarum, $A$. apis and $P$. infestans and moderate activity against $B$. cinerea (60.0\% growth inhibition) and $R$. solani $(80.0 \%)$. The best result for FEO-POL was achieved against $S$. sclerotiorum $(100.0 \%)$. It is interesting to note that FEO-EG did not inhibit the mycelia growth of $S$. sclerotiorum $(0 \%)$. Different activities against this pathogen could be the result of the presence of trans-anethole as a main component in FEO-POL, which was not detected in FEO-EG. The activity of fennel essential oil with high trans-anethole content against $S$. sclerotiorum was also observed by other researchers ${ }^{13}$.

The obtained results indicate that FEO-POL may find application as an efficient bio-fungicide against the pathogenic fungus $S$. sclerotiorum, which causes stem and root rot. This disease is a significant threat for over 400 species of plants including tomatoes, soybeans, sunflowers and green beans. The pathogen produces structures known as sclerotia or white mould, which can affect young seedlings, mature plants and fruits during storage. It can spread quickly from plant to plant, especially in glasshouses, where high humidity is present. S. sclerotiorum is one of the world's most dangerous plant pathogens due to its effect on flowers, leaves, fruits or stems ${ }^{13}$.

FEO-POL was found to inhibit the growth of $R$. solani. This soil-borne pathogen is known for attacking plants in their early stages of development, such as seeds and seedlings, and causing various plant diseases, e.g. collar rot and damping off. It attacks crops of popular plants such as potatoes, cucumbers and tomatoes, and may cause serious plant losses by destroying their roots and stems. Chemical control of this pathogen is not completely effective, and the damage caused by $R$. solani remains a persistent problem. Formulations of biofungicides may be a good solution for this problem ${ }^{26}$, and our results suggest that one of their components may be fennel essential oil.

In the present study, FEO-POL also exhibited moderate activity against $B$. cinerea, an airborne plant pathogen causing grey mould, which attacks over 200 crops worldwide, including wine grapes, strawberries and other fruits. Although there are some fungicides for its control, many of them fail due to its genetic plasticity. Aminifard and Mohammadi ${ }^{27}$ found that black caraway, peppermint and fennel essential oils inhibited the infection of plum fruits by $B$. cinerea. The results also suggest that the application of the tested essential oil could be helpful in increasing the storage life of some fruits, possibly in combination with other essential oils in order to improve its activity.

\section{CONCLUSIONS}

The results demonstrate that the two tested essential oils from fruits of fennel cultivated in Poland and Egypt are two distinct chemotypes, which significantly differ in their content, composition and fungicidal activity. The high content of estragole in fennel fruits from Egypt makes this plant material to be less valuable for consumption and medicinal applications. Its antifungal activity against tested fungi was also weak. In contrast, essential oil from Polish plant material, containing as its main components trans-anethole and fenchone, showed better activities against all tested fungi, especially against $S$. sclerotiorum, R. solani and B. cinerea. FEO-POL may be a good candidate for application as a bio-fungicide and can be an alternative to the chemical fungicides used currently against these pathogenic fungi.

\section{ACKNOWLEDGEMENTS}

The authors are grateful to Plant Herb "KAWON-HURT" Nowak sp.j. from Gostyń (Poland) and Justyna Kolak for providing the plant material for testing. Research was supported by the Ministry of Science and Higher Education (Poland) as part of the statutory activities of the Faculty of Chemical Technology and Engineering of the West Pomeranian University of Technology, Szczecin.

\section{LITERATURE CITED}

1. Raal, A., Orav, A.M. \& Arak, E. (2012). Essential oil composition of Foeniculum vulgare Mill. fruits from pharmacies in different countries. Nat. Prod. Res. 26(13), 1173-1178. DOI: 10.1080/14786419.2010.535154.

2. Mimica-Dukić, N., Kujundžić, S., Soković, M. \& Couladis, M. (2003). Essential oil composition and antifungal activity of Foeniculum vulgare Mill. obtained by different distillation conditions. Phytother. Res. 17(4), 368-371. DOI: 10.1002/ptr.1159.

3. Shahat, A.A, Ibrahim, A.Y., Hendawy, S.F., Omer, E.A., Hammouda, F.M., Abdel-Rahman, F.H. \& Saleh, M.A. (2011). 
Chemical composition, antimicrobial and antioxidant activities of essential oils from organically cultivated fennel cultivars. Molecules 16(2), 1366-1377. DOI: 10.3390/molecules16021366.

4. Özbek, H., Uğraş, S., Dülger, H., Bayram, I., Tuncer, I., Öztürk, G. \& Öztürk, A. (2003). Hepatoprotective effect of Foeniculum vulgare essential oil. Fitoterapia 74(3), 317-319. DOI: 10.1016/S0367-326X(03)00028-5.

5. Anand, P., Kunnumakara, A., Sundaram, C., Harikumar, K., Tharakan, S., Lai, O., Sung, B. \& Aggarwal, B. (2008). Cancer is a preventable disease that requires major lifestyle changes. Pharmaceut. Res. 25(9), 2097-2116. DOI: 10.1007/ s11095-008-9661-9.

6. Pradhan, M., Sribhuwaneswari, S., Karthikeyan, D., Minz, S., Sure, P., Chandu, A.N., Mishra, U., Kamalakannan, K., Saravanankumar, A. \& Sivakumar, T. (2008). In-vitro cytoprotection activity of Foeniculum vulgare and Helicteres isora in cultured human blood lymphocytes and antitumour activity against B16F10 melanoma cell line. Research J. Pharm. and Tech. 1(14), 450-452.

7. Ruberto, G., Baratta, M.T., Deans, S.G. \& Dorman, H.J.D. (2000). Antioxidant and antimicrobial activity of Foeniculum vulgare and Crithmum maritimum essential oils. Planta Med. 66, 687-693. DOI: 10.1055/s-2000-9773.

8. Javed, S., Mushtaq, S., Khokhar, I., Ahmad, R. \& Haider, M.S. (2012). Comparative antimicrobial activity of clove and fennel essential oils against food borne pathogenic fungi and food spoilage bacteria. Afr. J. Biotechnol. 11(94), 16065-16070. DOI: $10.5897 / A J B 11.3058$.

9. Diao, W.R., Hu, Q.P., Zhang, H. \& Xu, J.G. (2014). Chemical composition, antibacterial activity and mechanism of action of essential oil from seeds of fennel (Foeniculum vulgare Mill.). Food Control 35(1), 109-116. DOI: 10.1016/j. foodcont.2013.06.056.

10. Kooti, W., Moradi, M., Ali-Akbari, S., Sharafi-Ahvazi, N., Asadi-Samani, M. \& Ashtary-Larky, D. (2015). Therapeutic and pharmacological potential of Foeniculum vulgare Mill: a review. J. Herb. Med. Pharmacol. 4(1), 1-9.

11. Al-Hadid, K.J. (2017). Quantitative analysis of antimicrobial activity of Foeniculum vulgare: A review. Plant Omics J. 10(1), 28-36. DOI: 10.21475/poj.10.01.17.322.

12. Singh, G., Maurya, S., de Lampasona, M.P. \& Catalan, C. (2006). Chemical constituents, antifungal and antioxidative potential of Foeniculum vulgare volatile oil and its acetone extract. Food Control 17(9), 745-752. DOI: 10.1016/j.foodcont.2005.03.010.

13. Soylu, S., Yigitbas, H., Soylu, E.M. \& Kurt, Ş. (2007). Antifungal effects of essential oils from oregano and fennel on Sclerotinia sclerotiorum. J. Appl. Microbiol. 103(4), 1021-1030. DOI: 10.1111/j.1365-2672.2007.03310.x.

14. Rahimmalek, M., Maghsoudi, H., Sabzalian, M.R. \& Ghasemi Pirbalouti, A. (2014). Variability of essential oil content and composition of different Iranian fennel (Foeniculum vulgare Mill.) accessions in relation to some morphological and climatic factors. J. Agr. Sci. Tech. 16(6), 1365-1374.

15. Polish Pharmacopoeia (7th ed., 2006). Polish Pharmaceutical Society, Warsaw, vol. I, p. 325

16. Adams, R.P. (2007). Identification of essential oil components by gas chromatography/mass spectrometry (4th ed.). Allured Publ. Corp., Carol Stream, IL, pp. 10-51.

17. Babushok, V.I., Linstrom, P.J. \& Zenkevich, I.G. (2011). Retention indices for frequently reported compounds of plant essential oils. J. Phys. Chem. Ref. Data 40 (art. no.043101), 1-47. DOI: $10.1063 / 1.3653552$.

18. Piccaglia, R. \& Marotti, M. (2001). Characterization of some Italian types of wild fennel (Foeniculum vulgare Mill.). J. Agric. Food. Chem. 49(1), 239-244. DOI: 10.1021/jf000636+. 19. Telci, I., Demirtas, I. \& Sahin, A. (2009). Variation in plant properties and essential oil composition is sweet fennel (Foeniculum vulgare Mill.) fruits during stages of maturity. Ind. Crops Prod. 30(1), 126-130. DOI: 10.1016/j.indcrop.2009.02.010.
20. Moradi, R., Moghaddam, P.R., Mahallati, M.N. \& Nezhadali, A. (2011). Effects of organic and biological fertilizers on fruit yield and essential oil of sweet fennel (Foeniculum vulgare var. dulce). Span. J. Agric. Res. 9(2), 546-553. DOI: 10.5424/sjar/20110902-190-10.

21. Afify, A.E.-M.M.R., El-Beltagi, H.S., Hammama, A.A.E., Sidky, M.M. \& Mostafa, O.F.A. (2011). Distribution of trans-anethole and estragole in fennel (Foeniculum vulgare Mill) of callus induced from different seedling parts and fruits. Not. Sci. Biol. 3(1), 79-86. DOI: 10.15835/nsb315422.

22. Aggarwal, B.B., Kunnumakkara, A.B., Harikumar, K.B., Tharakan, S.T., Sung, B. \& Anand, P. (2008). Potential of spice-derived phytochemicals for cancer prevention. Planta Med. 74(13), 1560-1569. DOI: 10.1055/s-2008-1074578.

23. Vincenzi, M., Silano, M., Maialetti, F. \& Scazzocchio, B. (2000). Constituents of aromatic plants: II. Estragole. Fitoterapia 71(6), 725-729. DOI: 10.1016/S0367-326X(00)00153-2.

24. Gori, L., Gallo, E., Mascherini, V., Mugelli, A., Vannacci, A. \& Firenzuoli, F. (2012). Can estragole in fennel seed decoctions really be considered a danger for human health? A fennel safety update. Evid-based Complement. Altern. Med. 2012(art. no. 860542), 1-10. DOI: 10.1155/2012/860542.

25. Ponte, E.L., Sousa, P.L., Rocha, M.V.A.P., Soares, P.M.G., Coelho-de-Souza, A.N., Leal-Cardoso1, J.H. \& Assreuy, A.M.S. (2012). Comparative study of the anti-edematogenic effects of anethole and estragole. Pharmacol. Rep. 64(4), 984-990. DOI: 10.1016/S1734-1140(12)70895-2.

26. Chung, W.C., Huang, J.W. \& Huang, H.C. (2005). Formulation of a soil biofungicide for control of damping-off of Chinese cabbage (Brassica chinensis) caused by Rhizoctonia solani. Biol. Control 32(2), 287-294. DOI: 10.1016/j.biocontrol.2004.10.011.

27. Aminifard, M.H. \& Mohammadi, S. (2013). Essential oils to control Botrytis cinerea in vitro and in vivo on plum fruits. $J$. Sci. Food Agric. 93(2), 348-353. DOI: 10.1002/jsfa.5765. 